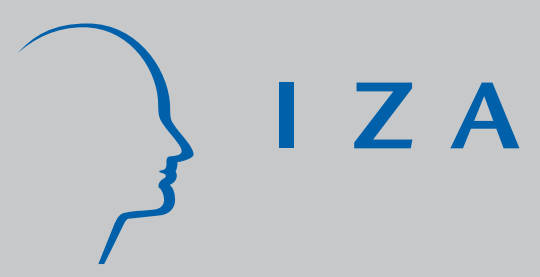

IZA DP No. 3810

Is It Your Foreign Name or Foreign Qualifications? An Experimental Study of Ethnic Discrimination in Hiring

Magnus Carlsson

Dan-Olof Rooth

November 2008 


\title{
Is It Your Foreign Name or Foreign Qualifications? An Experimental Study of Ethnic Discrimination in Hiring
}

\author{
Magnus Carlsson \\ Kalmar University \\ Dan-Olof Rooth \\ Kalmar University \\ and IZA
}

Discussion Paper No. 3810

November 2008

\author{
IZA \\ P.O. Box 7240 \\ 53072 Bonn \\ Germany \\ Phone: +49-228-3894-0 \\ Fax: +49-228-3894-180 \\ E-mail: iza@iza.org
}

\begin{abstract}
Any opinions expressed here are those of the author(s) and not those of IZA. Research published in this series may include views on policy, but the institute itself takes no institutional policy positions.

The Institute for the Study of Labor (IZA) in Bonn is a local and virtual international research center and a place of communication between science, politics and business. IZA is an independent nonprofit organization supported by Deutsche Post World Net. The center is associated with the University of Bonn and offers a stimulating research environment through its international network, workshops and conferences, data service, project support, research visits and doctoral program. IZA engages in (i) original and internationally competitive research in all fields of labor economics, (ii) development of policy concepts, and (iii) dissemination of research results and concepts to the interested public.
\end{abstract}

IZA Discussion Papers often represent preliminary work and are circulated to encourage discussion. Citation of such a paper should account for its provisional character. A revised version may be available directly from the author. 
IZA Discussion Paper No. 3810

November 2008

\section{ABSTRACT \\ Is It Your Foreign Name or Foreign Qualifications? An Experimental Study of Ethnic Discrimination in Hiring}

This paper contributes to the existing literature on ethnic discrimination of immigrants in hiring by addressing the central question of what employers act on in a job application. The method involved sending qualitatively identical resumes signalling belonging to different ethnic groups to firms advertising for labour. The results show that whether the applicant has a native sounding or a foreign sounding name explains approximately 77 per cent of the total gap in the probability of being invited to an interview between natives and immigrants, while having foreign qualifications only explains the remaining 23 per cent. This in turn, suggests a lower bound for statistical discrimination of approximately 23 per cent of total discrimination. The analysis indicates further that the 77 per cent are most likely driven by a mixture of preference-based and statistical discrimination.

JEL Classification: J64, J71

Keywords: ethnic discrimination, hiring, job search, preference-based discrimination, statistical discrimination, correspondence testing

Corresponding author:

Magnus Carlsson

Baltic Business School

Kalmar University

39182 Kalmar

Sweden

E-mail: magnus.carlsson@hik.se

\footnotetext{
* We thank Stefan Eriksson, Martin Nordin and participants at seminars at the Department of Economics at University College London, as well as participants at the 2008 European Society for Population Economics Conference in London for their valuable comments. Terese Johansson provided excellent research assistance. A research grant from the Swedish Council for Working Life and Social Research is gratefully acknowledged.
} 


\section{Introduction}

Ethnic discrimination against immigrants in employment situations is obviously an important subject to study. Discrimination is for example associated with welfare losses to society because of poor matches between employers and employees, as well as individual costs to job seekers. Previous studies in a significant number of countries have showed that ethnic discrimination in hiring exists. ${ }^{1}$ In the case of Sweden, an example is Carlsson and Rooth (2007) who find that the probability of being invited to interview is 10 percentage points lower for a native applicant with a Middle Eastern background than an applicant with a Swedish background.

However, from the results of Carlsson and Rooth (2007) it is unclear, firstly, whether immigrants are exposed to discrimination in a larger extent compared to natives with a foreign background and, secondly, what factors drive discrimination of immigrants. This study takes one important step forward by approaching the second question, while an answer to the first question is provided as a by-product. More specifically, the study aims to determine what characteristics of an immigrant job applicant an employer acts on. In fact, holding all other qualifications constant, there are only two characteristics distinguishing an immigrant's job application from a native's job application: the applicant's name (either native or foreign sounding) and the applicant's qualifications (either obtained in the home country or in a foreign country). Determining the relative importance of these two factors in explaining employer discrimination is the main goal of the study. The results may, in turn, indicate to what degree preference-based and statistical discrimination is present, which constitutes crucial information for policy makers in counteracting discrimination. Focus of the study is on male individuals with a Middle Eastern background, since surveys show that this group is probably one of the most likely to experience discrimination in Sweden (Lange, 2000).

To our knowledge, there exists only one previous study trying to separate discrimination in employment situations into different parts, conducted by Weichselbaumer (2004) in the Austrian labour market. However, Weichselbaumer (2004) focuses on sex discrimination, applying a rather different approach where the

1 See Riach and Riach (2002) for a summary of studies testing for discrimination in employment situations 
author tries to emphasise personality in job applications with the aim of influencing sex stereotypes, and thus identifying preference-based discrimination from statistical discrimination. From the results, the author concludes that preferencebased discrimination is most likely the source of the unequal treatment of females in hiring.

The method applied in this study is the correspondence testing (henceforth CT) method, whereby qualitatively identical fictitious resumes from applicants belonging to different ethnic groups, typically signalled through the name of the applicant and possibly other information, are sent to employers advertising for labour. A difference in the callback rate ${ }^{2}$ between the groups is interpreted as discrimination. The main advantage of using CT is that the method guarantees that the researcher observes the same characteristics of the applicants as the employers do, and can thereby control for them. This is usually not possible if register data are analysed.

Our strategy for indentifying the impact of the two factors of interest is to send three qualitatively identical job applications to employers advertising for labour: one belongs to a native with a Swedish-sounding name, one belongs to a native with a Middle Eastern-sounding name, and one belongs to an immigrant from the Middle East.

The results show that approximately 77 per cent of discrimination against immigrants is explained by employers acting on the name of the applicant per se, while the remaining 23 per cent is explained by employers acting on the applicant's foreign qualifications. This suggests a lower limit for statistical discrimination of 23 per cent of total discrimination, while the upper limit theoretically is 100 percent. Nevertheless, the results indicate that the true degree of statistical discrimination rather lies somewhere in-between these boundaries. Apparently, both statistical and preference-based discrimination are relevant factors in explaining discrimination of immigrants in employment situations. Furthermore, the results reveal that if the recruiter is male, or there is a higher share of male employees at the firm, the probability of being invited to interview is lower for applicants with a Middle Eastern background. In contrast, staffing companies are more inclined to invite applicants with a Middle Eastern background to interview.

2 The number of sent applications relative to the number of invitations to interview. 
This paper is organised as follows. Section 2 briefly presents the concepts of preference-based and statistical discrimination. In Section 3, the design of the experiment and the data collection are described. Section 4 presents the descriptive statistics, and in Section 5 follows the empirical analysis. Finally, interpretations and conclusions are presented in Sections 6 and 7 respectively.

\section{Theories of Discrimination}

The two main theories of economic discrimination are preference-based and statistical discrimination (Altonji and Blank, 1999). The pioneering work on economic discrimination is by Becker (1957), which is based on the concept of preference- or taste-based discrimination. In his framework, employers, customers or co-workers belonging to the majority have negative preferences towards minority workers (or a taste for majority workers).

In the case of employer discrimination, an additional cost is incurred to hire workers from the minority group because of the employer's preferences. This results in less demand for minority member workers given equal wages for the two groups. In the case of customer discrimination, buyers are willing to pay a higher price for engaging in transactions with majority members instead of minority members. Finally, in the case of co-worker discrimination, majority workers demand a higher wage to work beside minority member workers. Based on this theory, discrimination against minority members can occur even if the majority and the minority members' expected productivity is the same and is observed with the same precision.

The other main type of discrimination is statistical discrimination (Phelps, 1972; Arrow, 1973). The main idea behind this theory is that an individual's productivity is observed with different precision depending on the individual's group belonging. Therefore, in order to predict the individual's productivity, the employer weights the productivity signalled by the individual and the average productivity of the group, which is assumed to be known. How the employer selects the weights depends upon the precision with which the individual's productivity is observed. As a result, demand for workers belonging to the minority group may be lower. This theory is 
also applicable in the case where the average productivity of the group is unknown, in which case the true average productivity of the group is replaced by the employer's beliefs about the average productivity.

\section{The Experiment}

For identifying the impact of the applicant's name per se and the impact of foreign qualifications on the probability of being invited to an interview, three qualitatively identical job applications were sent to employers advertising for labour, the first belonging to a native with a Swedish-sounding name, the second belonging to a native with a Middle Eastern-sounding name, and the last belonging to an immigrant with foreign qualifications from the Middle East and a Middle Easternsounding name.

Based on the construction of the experiment, if a difference in callback rate is found between the two native candidates, it is possible to conclude that the employers act on the applicant's name. Moreover, if the applicant's name per se is an important variable in the hiring decision, it may suggest that employers have negative attitudes towards individuals with Middle Eastern-sounding names, and hence that preference-based discrimination is present. However, the identifying assumption is that the applications contain complete information regarding all relevant productive characteristics of the candidates. Whether this is a reasonable assumption depends largely on how the applications are constructed, which is discussed in the next section. In the case of incomplete information, or if the information is not acquired by the recruiter, employer stereotypes and the name of the applicant may nonetheless be utilised to predict the productivity of the applicant, and statistical discrimination will be present.

On the other hand, interpreting a difference in callback rate between the native with a Middle Eastern-sounding name and the immigrant is more straightforward. A difference must be due to statistical discrimination since the two applicants share 
the same ethnicity, ruling out preferences as the source, and have identical levels of qualifications, although the qualifications were obtained in different countries. ${ }^{3}$

The following sub-sections describe the choice of the occupations included in the experiment, the applications, and data gathering.

\subsection{Choice of Occupations}

It is important that the number of occupations included in the experiment is as high as possible in order to obtain a result representative of the labour market as a whole, including occupations with different skill levels and different shares of immigrants. However, to make satisfactory progress in the collection of cases it was also necessary that the demand for labour was high enough in the chosen occupations. In the end, the experiment was restricted to 11 occupations: shop sales assistants, construction workers, restaurant workers, motor-vehicle drivers, accountants, teachers (preschool, compulsory school math/science and secondary school), business sales assistants, computer professionals, and nurses.

\subsection{Construction of Applications}

The starting point in the construction of the applications was a number of real-life written resumés available on the Web page of the Swedish Employment Agency. These were used as templates and adjusted and calibrated for our purposes in order to obtain a pool of standardised applications for each occupation. In the end, all applications consisted of a biography on the first page and a detailed CV of education and work experience on the second page. ${ }^{4}$

In order to minimise the probability that the employers utilise the name of the applicant to predict left out variables, the applications were constructed to be very detailed regarding all qualifications. They clearly state what is expected to be relevant information regarding the qualifications by an employer. In short, the applications were constructed so that it is evident that the fictitious candidates

3 Immigration from the Middle East is a relatively recent phenomenon in Sweden, which began in a larger scale in the 1980s. Therefore, it is reasonable to assume that native Swedes view first and second generation immigrants from the Middle East as belonging to the same ethnicity.

4 See Appendix B for example applications. 
possess the education required for the occupation. Furthermore, all information about previous work experience is precisely expressed, including the number of employers, the length of employment, and the tasks undertaken at previous workplaces. The resumés also contain clear information regarding the candidate's summer jobs during education, computer literacy, language skills in Swedish and English, and driving license, and signal a person that is motivated, ambitious, capable, and creative. All application materials, including the covering letter, were written in a high level of Swedish to give the impression that the applicant is highly qualified. ${ }^{5}$ The only difference was where the qualifications of the two applicants with Middle Eastern-sounding names were obtained.

Regarding the age of the applicants, it was decided that this study would analyse job seekers at the beginning of their working career. This decision was justified by the fact that it would be very challenging to construct CVs for older applicants, covering a significant period of a whole working career, and still argue that the applicants' qualifications are identical. In addition, the immigrant population in Sweden with a Middle Eastern background tends to be young. Therefore, it is reasonable to study individuals who have recently entered the labour market.

However, at the same time, the applicants still needed to have some work experience in the occupation that they applied for, since severe competition from other applicants was expected. The candidates were therefore given between two and four years of work experience in the Swedish labour market, varying between occupations depending on the expected competition, but always the same number of years within an occupation. The candidates ended up being 22-28 years old, based on the length of their education and the amount of work experience in each occupation. The applicants' ages hence varied between occupations, but were the same within an occupation.

The choice of the names of the candidates, used to signal group belonging, is fundamental to CT methodology. Fortunately there is a clear distinction between typical Swedish names and Middle Eastern names. One of the most frequently

5 One concern is that the level of language skills for the immigrant is even too high, making the application implausible. 
occurring Swedish and three of the most frequently Middle Eastern names in Sweden were selected and used randomly. ${ }^{6}$

Regarding the construction of the immigrant's application, it was necessary to include some additional specific information. For example, the application contains a short paragraph stating that the job seeker is born in the Middle East, has a foreign language as their mother tongue, and has obtained education from a foreign country. Specific information about a high level of Swedish language skills was also added to ensure that the immigrant's application signalled the same level of productivity as the other resumés. ${ }^{7}$ It was therefore necessary for the immigrant's resumé to convey having spent sufficient time in Sweden and completed a language course in Swedish for immigrants called SFI. ${ }^{8}$

Moreover, for the immigrant's resumé to signal equal productivity to the other applications, it was necessary to detail that they were employed while studying the Swedish language, immediately after arriving in Sweden. Otherwise, the immigrant would appear less productive because of an employment gap. As a result, the immigrant applicant (as well as the other applicants) was given a minimum of two years' work experience in the Swedish labour market, which is the estimated time required to learn Swedish well.

To construct the immigrant's application it was also necessary to take into account that the nurses and construction workers occupations require evidence of qualification from relevant Swedish authority and association, respectively. Moreover, in the case of the remaining occupations requiring university education (computer professionals, accountants and all teachers occupations), for the immigrant to signal being equally qualified, it is appropriate to have the foreign university degree verified by the Swedish National Agency for Education. In all

6 We used the Swedish first name Erik and the last name Karlsson, and the Middle Eastern first names Ali, Ibrahim and Mohamed and the last names Ahmed, Hassan and Ismail, obtained from the Name Statistics Register (Statistics Sweden, 2005). A sensitivity analysis showed that neither different Middle Eastern names nor different resumés (within occupations) had a statistically significant effect upon the callback rate. The reason for using only a single typical Swedish name is that Carlsson and Rooth (2007) show that different typical Swedish sounding names have no significant impact on the callback rate.

7 There is in fact one qualitative difference, namely that the immigrant's application states language skills in Arabic while the other applications do not.

8 SFI (Svenska För Invandrare) is a basic language course for adult immigrants whose main language is not Swedish. 
these cases, the immigrant's application clearly states that the relevant authority or association has evaluated and authorised the foreign qualifications.

Finally, the applications had to contain contact information, so a telephone number and email address were attached to each application. These email addresses and telephone numbers (including an automatic answering service) were registered at a large Internet provider and telephone company. Since Carlsson and Rooth (2007) found that no employers sent invitations to interview by post, the applicants were given fictitious postal addresses in similar neighbourhoods.

\subsection{Data Gathering}

Between August 2006 and April 2007, all employment advertisements found on the Web page of the Swedish Employment Agency in the selected occupations in the two major labour market areas in Sweden, Stockholm and Gothenburg, were collected. ${ }^{9}$ For each advertisement, the first step was to pick three applications from the pool of standardised applications in the relevant occupation. Next, a Swedish-sounding name and two Middle Eastern-sounding names were randomly assigned to the applications. Thereafter, additional information about being an immigrant was added to one of the applications with a Middle Eastern-sounding name. Finally, the applications were sent to the employer in alternating order, usually with a one-day delay in-between. In total, 3,942 applications were sent to 1,314 employers. All invitations to interview were recorded and then immediately declined to minimise inconvenience for the employers.

Moreover, after the experiment was conducted, characteristics of the participating firms were gathered.10 These were partly obtained from the job ads, from where information could be retrieved on the sex of the recruiter, whether the firm is a staffing company or not, and whether the workplace is located in Stockholm or Gothenburg. The remaining characteristics were collected by identifying the workplaces in Statistics Sweden's Business Register using workplace IDs (so-called

9 In approximately 20 per cent of the job openings it was not possible to apply via email. These vacancies were excluded.

10 See Appendix A, Table A1, for descriptive statistics over firm characteristics. 
CFAR-no.; see www.scb.se). ${ }^{11}$ From the registers, data were obtained on the fraction of males at the firm, the number of employees in the workplace, the fraction of immigrants in the municipality where the workplace is located, and whether the firm is a public or private sector employer. 81.2 per cent or 1,067 out of 1,314 of the workplaces were successfully identified in the registers, resulting in 3,201 observations. ${ }^{12}$

\section{Descriptive Statistics}

With the two factors we wish to identify in mind, the figures in Table 1 compare the outcome for the two natives, and compare the outcome for the native with a Middle Eastern-sounding name and the immigrant. The former difference measures the effect of having a foreign name, while the latter measures the effect of having foreign qualifications.

$* * *$ Table 1 about here $* * *$

The last two rows of the table present the total result for the experiment, showing that 1,314 employers participated, corresponding to 3,942 job applications sent for the three candidates. The first row of these two compares the result for the two native applicants. In 728 cases none were invited (column 1), in 280 cases both were invited (column 2), in 265 cases only the native with a Swedish-sounding name was invited (column 3), and in 41 cases only the native with a Middle Easternsounding name was invited (column 4). The next two columns show that the callback rate is 0.41 for the native with a Swedish-sounding name and 0.24 for the native with a Middle Eastern-sounding name, implying a difference in callback rate of 17 percentage points (see last column).

In the second row of the two, the native applicant with a Middle Easternsounding name and the immigrant applicant are compared. Neither were invited in

11 Company IDs were identified from combining information on firm name and address found in the job ad with information in Statistics Sweden's Business Register available on the Internet.

12 Approximately 10 per cent of the workplaces could not be identified because either we could not identify the CFAR-no. or Statistics Sweden could not find a match given the CFAR-no. The remaining missing 8.8 per cent could not be identified because the firm had recently started and Statistics Sweden had no data available. 
927 cases (column 1), both were invited in 193 cases (column 2), only the native with a Middle Eastern-sounding name was invited in 128 cases (column 3), and only the immigrant was invited in 66 cases (column 4). From the next two columns it can be read that the callback rate for the native with a Middle Eastern-sounding name is (still) 0.24 and for the immigrant is 0.20 . The difference in callback rate in this case is hence only four percentage points (see last column).

The remaining 11 blocks (of two rows each) in the table present the results in a similar way, but for each occupation separately. Considering the native applicants first, the difference in callback rate between the two is largest for teachers (math and science), construction workers, computer professionals, and motor vehicle drivers and smallest for preschool teachers.

Next, when the native with a Middle Eastern-sounding name and the immigrant are compared, it emerges that the difference in callback rate is generally much smaller, but still positive for all occupations except motor-vehicle drivers. The largest differences are found for teachers (math and science) and computer professionals.

\section{Empirical Analysis}

First, this section analyses differences in the probability of being invited to interview for the three applicants by estimating linear probability models on all observations. ${ }^{13}$ Second, firm-specific attributes are analysed using probit models in order to determine which variables, if any, are associated with treating the applicants differently. The purpose is to investigate what characterises employers that act on the name of the applicant and/or in which country the applicant's qualifications are obtained.

\subsection{Differences in Callback Rate}

To analyse differences in callback rate between the applicants, the callback dummy is first regressed on a constant and two dummy variables equal to one if the application belongs to a native with a Swedish sounding name or an immigrant

13 The linear probability model is completely general in this case since the explanatory variables consist of dummy variables for mutually exclusive and exhaustive categories (see Wooldridge, 2002) 
respectively, else equal to zero. Hence, the native with a Middle Eastern-sounding name constitutes the reference group, providing a convenient way to discern the difference between the native with a Swedish-sounding name and the immigrant applicant based on the two desired factors - explained by the name of the applicant and uncertainty about foreign qualifications.

On the last row of Table 2 is reported, firstly, the callback rate for the benchmark, the native with a Middle Eastern sounding name, being equal to 24 per cent, secondly, the difference in callback rate for the native applicant with a Swedish-sounding name, being on average 17 percentage points higher compared to the reference group, and thirdly, the difference in callback rate for the immigrant, being on average five percentage points lower compared to the reference group. Both of the differences in callback rate are statistically significant at the one per cent level.

$* * *$ Table 2 about here $* * *$

Next, in order to analyse whether differences in the probability of being invited to interview varies between occupations, the same model is estimated for the observations in each of the 11 occupations. From the first column in Table 2 it can be seen how the invitation probability varies over occupations for the reference group, the native with a Middle Eastern-sounding name. The lowest probability is found in the shop sales assistant occupation followed by the restaurant workers and construction workers occupations, while the highest probabilities are found in the occupations preschool teachers and computer professionals.

The second column reports, for each occupation, the difference in callback rate between the two native applicants. The probability of being invited is significantly higher for a native with a Swedish-sounding name in all occupations. The largest differences are found in the occupations teachers (math and science), construction workers, computer professionals, and motor vehicle drivers, where the difference varies between 23 and 30 percentage points. The smallest differences on the other hand are found in the occupations preschool teachers, secondary school teachers and shop sales assistants, where the difference varies between 11 and 15 percentage 
points. For the remaining occupations, the difference in callback rate lies somewhere between these two extreme groups.

Column 3 reports the corresponding difference, for each occupation, between the native with a Middle Eastern sounding name and the immigrant. It is clear from the estimates that in 5 out of 11 occupations, the immigrant faces a significantly lower probability of being invited to interview compared to the reference group. The largest difference in the probability of being invited is found in the teachers (math and science) occupation, where immigrants face a 17-percentage-point-lower probability of being invited to interview compared to the native with a Middle Eastern-sounding name. The other four significant differences in callback rate are in the range of 4 to 14 percentage points (restaurant workers, business sales assistants, preschool teachers, and computer professionals). For the remaining six occupations, no significant difference in callback rate is found between the immigrant and the native with a Middle Eastern-sounding name.

Finally, as will become evident in the interpretations section, it is of interest to analyse whether these differences in callback rates are correlated with variables such as the share of females in the occupation, the share of foreign born in the occupation, the skill level of the occupation, and the tightness of the labour market in the occupation. For labour market tightness in an occupation, the callback rate of the native applicant with a Swedish sounding name is used as a proxy. ${ }^{14}$ It is a reasonable approximation under the assumption that no discrimination occurs against this applicant, since in occupations where fewer applications are received by employers the callback rate will be higher, and vice versa.

Turning to the estimated correlations, the difference in callback rate between the two native applicants is statistically significantly negatively correlated with the share of females in the occupation (-0.53 and significant at the ten per cent level, see Table A2). No association is however found with any of the other variables.

14 Indeed, this proxy is significantly positively correlated with the Swedish Employment Agency's index for occupational labour shortage for the period (see The Swedish Employment Agency, 2007), which yields the same empirical results (which are available upon request). 
Considering the difference in callback rate between the two individuals with a Middle Eastern sounding name, no significant relationship is found with any of the variables.

\subsection{Factors Associated with Differences in Callbacks}

To analyse which, if any, firm-specific attributes are associated with treating the applicants differently, probit models are estimated. The dependent variable is still the callback dummy and the explanatory variables comprise the firm/workplace characteristics and the group indicators, as well as interactions between the two categories.

However, to start with, we analyse which firm characteristics in general are associated with the probability of a callback. For this, the callback dummy is regressed on the firm characteristics alone, both without and with control for occupation. As is evident from the first two columns of Table 3, there are mainly two variables associated with the probability of being invited to interview. ${ }^{15}$ The probability is lower if the recruiter is male and higher if the firm is a staffing company. There is also evidence that the probability of being invited is slightly lower for workplaces with less than 20 employees and somewhat higher for workplaces located in Stockholm.

*** Table 3 about here ***

Next, and more interesting, it is analysed which firm characteristics are associated with treating the three applicants differently. As previous sections have shown, employers do not appear to distinguish between the two applicants with a Middle Eastern-sounding name. Therefore, it is not expected that there are any characteristics significantly associated with treating them differently either. This is confirmed by the results of estimating Models 3 and 4 on only the observations of the two applicants with a Middle Eastern-sounding name. In both models, the native

15 The results presented are the estimated marginal changes in the probability for the continuous variables and estimated discrete changes for dummy variables. For convenience, both are simply referred to as marginal effects. 
applicant with a Middle Eastern-sounding name constitutes the reference group, and all firm characteristics are interacted with the immigrant dummy. As expected, the two applicants are very homogenous in respect to the firm-specific attributes that influence their callback rates. In fact, as is evident from the table, no characteristics at all are associated with treating them differently.

Therefore, in the final specification, all observations for the native with a Middle Eastern-sounding name and the immigrant are merged to form a new group: applicants with a Middle Eastern-sounding name. In Models 5 and 6, the callback dummy is regressed on the firm characteristics and on the interaction of the characteristics, with the indicator equal to one if the applicant has a Middle Eastern-sounding name and zero otherwise. The native applicant with a Swedishsounding name hence constitutes the reference group.

The estimated marginal effects show that three variables are significantly associated with the difference in probability of being invited to interview between the two groups (see Model 6). First, if a male is responsible for recruitment, as opposed to a female, a candidate with a Middle Eastern-sounding name has a fivepercentage-point-lower probability of being invited to interview compared to a native with a Swedish-sounding name (significant at the 10 per cent level).

The results also show that a higher share of males is associated with a lower probability of being invited to interview for job seekers with a Middle Easternsounding name. In Model 6, the estimated marginal effect is interpreted as follows: if the fraction of males at the firm increases by one percentage point, the probability of an applicant with a Middle Eastern-sounding name being invited to interview decreases by 0.12 percentage points compared to a native with a Swedish-sounding name.

Finally, staffing companies, in contrast to other firms, invite an applicant with a Middle Eastern-sounding name to interview with a 12-percentage-point-higher probability compared to natives with a Swedish-sounding name.

\section{Interpretations}

To interpret the results, the callback rates for the three applicants are compared. As expected, based on the results from previous studies of discrimination in the 
Swedish labour market, there is a difference in callback rate between the native with a Swedish-sounding name and the immigrant. More interestingly is, however, to divide this 22-percentage-point gap into the two parts of interest - explained by the immigrant applicant's foreign qualifications and foreign name.

Considering the uncertainty of the immigrant applicant's foreign qualifications, this factor explains five percentage points, or 23 per cent $\left(\approx \frac{5}{22}\right)$ (see Table 2 ) of the total gap, identified as the difference in callback rate between the native with a Middle Eastern-sounding name and the immigrant. This difference must be ascribed to statistical discrimination, since the applicants share the same ethnicity and have identical levels of qualifications, the only difference being in which country the qualifications are obtained.

Next, the remaining 17 percentage points of the total gap, or 77 per cent $\left(\approx \frac{17}{22}\right)$, are explained by the name of the applicant per se, identified as the difference in callback rate between the two native applicants. Hence, the applicant's name is more than three times more important than uncertainty about foreign qualifications in explaining the difference in callback rate between natives with a Swedishsounding name and immigrants. The natural, and possibly challenging, question that arises is how to explain why employers act on the name of the applicant. Initially, it may appear that preference-based discrimination is the explanation. After all, the applications states identical qualifications, all obtained in Sweden, on a very detailed level and, as a result, little room should be left for employers to exercise statistical discrimination based on the name of the applicant.

However, there at least three concerns associated with equating employers acting on the name of the applicant with preference-based discrimination: firstly, how to explain that the impact of the name of the applicant varies over occupations, secondly, incomplete information about qualifications can still be an issue, and thirdly, potentially there are employers who uses the name of the applicant as a screening device without acquiring the information in the application.

The first issue, the observation that the impact of the applicant's name varies over occupations may be explained by a varying degree of preference-based 
discrimination. Interestingly, the statistically significantly negative correlation found between the impact of the name and the share of females in the occupation shows that the name of the applicant is less important whenever the share of females is larger. One interpretation of this correlation is that females have preferences that are more positive to individuals with a Middle Eastern sounding name and hence co-worker preference-based discrimination declines with the share of females. Indeed, this being the case is supported by the analysis of firm specific characteristics, showing that the probability of being invited to interview is lower for applicants with a Middle Eastern-sounding name, if the recruiter is male or when the share of males at the firm is higher. Presumably, this observation is explained by females having more positive attitudes towards immigrants. The alternative, that females exercise statistical discrimination to a lesser extent, seems far-fetched since there is no reason to expect that females have any information about immigrants' productivity that males do not. The Swedish Integration Board (2005) survey also supports the assertion that preferences are the explanation for this phenomenon. The survey shows that in general, males in Sweden have more negative attitudes towards immigrants than females. In short, the correlation between the impact of the name of the applicant and the share of females in the occupation suggests that preferences indeed may vary over occupations.

Alternatively, statistical discrimination must vary over occupations. Carlsson and Rooth (2007) suggest that that the degree of statistical discrimination may be lower in highly skilled occupations, since the applications in these occupations in general are more detailed about qualifications. This, in turn, is expected to reduce uncertainty about the qualifications, and as a result diminish the occurrence of statistical discrimination. With the data available in this study, the validity of this suggestion can be tested. For doing this, the difference in callback rate between the two candidates with a Middle Eastern-sounding name is utilised, which is guaranteed to be driven by statistical discrimination. The correlation, however, between this measure of statistical discrimination and the skill level of the occupation shows no statistically significant relationship (see Table A2). The interpretation is that there is no support for statistical discrimination varying over occupations. 
Summing up the discussion of the first issue, this variation of the impact of the name of the applicant appears to be in line with preference-based discrimination and does therefore at least not contradict the interpretation of employers acting on the name of the applicant as preference-based discrimination.

The second concern of interpreting the impact of the name was potentially incomplete information about the candidates' qualifications, which may result in statistical discrimination. The reason is that, although the applications aim being very detailed on all relevant productive characteristics, it is difficult to claim that no relevant information is missing. Whenever an employer experiences that some important variable is left out or imprecisely expressed in the application, the name of the applicant may be used for predictions. For instance, regarding the native applicant with a Middle Eastern sounding name, the employer may have concerns about the language skills, even though the resume clearly signals a high level of the Swedish language. However, whether employer indeed experience that important variables are missing is obviously difficult to test for. In summary, statistical discrimination is likely to explain why employers act on the name of the applicant to some extent.

The third issue complicating the interpretation of employers acting on the name of the applicant is the potential existence of employers performing screening using the name of the applicant. Such screening may be motivated by a cost minimising argument, if a significant number of applications are received. ${ }^{16}$ One strategy for finding a qualified applicant efficiently may be to initially perform a rough sorting, using the name of the applicant as a sorting device without examining the applications in greater detail. For instance, employers may believe that candidates with a Swedish sounding name are on average more qualified than candidates with a Middle Eastern-sounding name. As a result, only applications with Swedish sounding names will in this case be selected for further examination and thus statistical discrimination is present. Interestingly, the data suggest a way to test whether employers indeed use such a strategy, since employers who receive fewer

16 No exact information regarding the number of applications the employers received is available. However, in some cases the employers responded to the applicants not only by informing whether invited to interview or not, but also giving general information about the recruitment process, such as the number of applications received, which in several occasions where hundreds. 
applications, in occupations with a tighter labour market, are expected to use less screening. Less screening will, in turn, result in a smaller difference in callback rate between the native applicants. As motivated in the empirical analysis section, the callback rate for the applicant with Swedish background is utilised as a proxy for labour market tightness. However, no significant correlation is found between the proxy and the difference in callback rate between the two native applicants. ${ }^{17}$ Hence, there is no support for the hypothesis that employers exercise statistical discrimination by using the name of the applicant as an initial screening device. Nevertheless, it could still be the case that employers use screening, unrelated to the number of applications received, as long as the number of applications with, for instance, a Swedish sounding name exceeds a certain threshold.

Summarising these three issues regarding the interpretation of the gap in callback rate between the two native applicants, the discussion suggests that the difference in callback rate between the two native applicants is most likely driven by a mixture of preference-based and statistical discrimination. In the extreme case, the difference can either be completely explained by preference-based discrimination or by statistical discrimination. Consequently, of the total gap in callback rate between the native applicant with a Swedish sounding name and the immigrant applicant, 23 per cent, constitutes a lower bound for statistical discrimination, while the upper bound is theoretically 100 per cent. Whatever remains of the total gap must be explained by preference-based discrimination.

Regarding policy implications for combating discrimination, the results clearly suggest that statistical discrimination is an issue, the lower bound for statistical discrimination being 23 per cent of total discrimination. One way to go for authorities is to invest effort in improving the possibility for immigrants to verify foreign qualifications. Interestingly, staffing companies were found to be more likely to invite immigrants, compared to other firms. An explanation is that these firms presumably have more experience of hiring situations, and particularly in employing immigrants. They may also have more a comprehensive recruitment procedure and be more concerned about the reputation of the firm since the primary business

17 As reported in the empirical analysis section, a measure of labour shortage has also been used as a proxy. This did not, however, chance the result. 
consists of recruitment. Potentially, if staffing companies were to appoint a higher share of vacancies in the labour market, ethnic discrimination in hiring may decline.

Most likely, employer preferences play a role as well in explaining the remaining 77 per cent of the total gap in callback rate between native and immigrant applicants. Hence, changing employers' and co-workers' attitudes towards immigrants seems also relevant for policy makers. The finding that the probability for applicants with a Middle Eastern background is lower if the recruiter is male or if the share of males at the firm is higher suggests that applicants with a foreign background may gain from a less sex segregated labour market where females may have more influence on hiring decisions.

\section{Conclusions}

The literature on economic discrimination shows that in several countries, including Sweden, ethnic discrimination in hiring exists. Indeed, it is an important subject to study since discrimination in employment situations disrupts the allocation of resources in the labour market, which affects the overall performance of the economy. However, in counteracting discrimination effectively, the source of discrimination must be identified at a first stage. This study goes one step further than previous studies on ethnic discrimination in hiring by using the CT method to analyse the central question of what drives discriminatory behaviour. The focus is on male immigrants from the Middle East since this group probably is one of the most exposed to discrimination in the Swedish labour market.

The results suggest a lower bound for statistical discrimination of 23 per cent of total discrimination, corresponding to the share of discrimination explained by uncertainty about immigrants' foreign qualifications. The remaining 77 per cent, explained by the immigrant's name per se, appear to be driven by a mixture of preference-based and statistical discrimination.

The policy implication is that if authorities wish to counteract ethnic discrimination in hiring, a variety of measures seems required. Obviously, to

minimise uncertainty about foreign qualifications, facilitating the possibility to verify and benefit from foreign qualifications is important, but also changing employers' attitudes towards immigrants in a more positive direction appear to be 
relevant. Interestingly, males' attitudes towards applicants with Middle Eastern background seem more negative than females', suggesting that ethnic discrimination may decrease if females would have more influence on hiring decisions. Moreover, the probability of being invited for applicants with a Middle Eastern background is larger when the firm is a staffing company. The explanation may be that such firms engage in recruitment on a daily basis and may therefore have a more comprehensive recruitment process compared to other employers. 


\section{References:}

Altonji, J., Blank, R. (1999), Race and gender in the labor market, In: Ashenfelter, O., Card, D. (Eds.), Handbook of Labor Economics. Elsevier, Amsterdam, pp. 31433259

Arrow, K.J. (1973), The theory of discrimination, In Ashenfelter and Rees, editors, discrimination in Labor Markets.

Becker GS. (1957), The economics of discrimination, Chicago: University of Chicago Press.

Carlsson M, Rooth D-O., (2007), Evidence of ethnic discrimination in the Swedish labor market using experimental data, Labour Economics ;14(4); 716-729.

Lange A. (2000), Diskriminering, integration och etniska relationer, Norrköping: Integrationsverket.

Phelps, E. (1972), The statistical theory of racism and sexism, American Economic Review;62; 659-61

Riach PA, Rich J., (2002), Field experiments of discrimination in the market place, The Economic Journal;112; F480-F518.

Swedish Employment Agency (2007), Var finns jobben 2007? Stockholm

Swedish Integration Board (2005), Integrationsbarometern, Norrköping.

Statistics Sweden (2003), Swedish Occupational Register, Stockholm: Statistics Sweden.

Statistics Sweden (2005), Swedish Name Register, Stockholm: Statistics Sweden.

Weichselbaumer D. (2004), Is it sex or personality? The impact of sex stereotypes on discrimination in applicant selection, Eastern Economic Journal;30; 159-186.

Wooldridge J. M. (2002), Econometric Analysis of Cross Section and Panel Data,. Cambridge, MA: MIT Press 


\section{Appendix A}

Table A1 Descriptive statistics of firm characteristics

\begin{tabular}{|c|c|c|c|c|c|c|c|c|}
\hline & \multicolumn{2}{|c|}{$\begin{array}{l}\mathrm{N}=3,201 \\
\quad \text { All } \\
\text { Callback } \\
\text { Equal to }\end{array}$} & \multicolumn{2}{|c|}{$\begin{array}{l}\mathrm{N}=1,067 \\
\text { Native S } \\
\text { Callback } \\
\text { Equal to }\end{array}$} & \multicolumn{2}{|c|}{$\begin{array}{l}\mathrm{N}=1,067 \\
\text { Native } \mathrm{M} \\
\text { Callback } \\
\text { Equal to }\end{array}$} & \multicolumn{2}{|c|}{$\begin{array}{c}\mathrm{N}=1,067 \\
\text { Immigrant } \\
\text { Callback } \\
\text { Equal to }\end{array}$} \\
\hline & 1 & 0 & 1 & 0 & 1 & 0 & 1 & 0 \\
\hline Male responsible & 0.41 & 0.59 & 0.47 & 0.59 & 0.36 & 0.60 & 0.35 & 0.59 \\
\hline Fraction Males & $\begin{array}{c}0.42 \\
{[0.33]}\end{array}$ & $\begin{array}{c}0.50 \\
{[0.31]}\end{array}$ & $\begin{array}{c}0.45 \\
{[0.33]}\end{array}$ & $\begin{array}{c}0.49 \\
{[0.30]}\end{array}$ & $\begin{array}{c}0.39 \\
{[0.32]}\end{array}$ & $\begin{array}{c}0.50 \\
{[0.31]}\end{array}$ & $\begin{array}{c}0.37 \\
{[0.33]}\end{array}$ & $\begin{array}{c}0.50 \\
{[0.31]}\end{array}$ \\
\hline Employed 0-19 & 0.51 & 0.60 & 0.52 & 0.61 & 0.51 & 0.59 & 0.48 & 0.59 \\
\hline Fraction Immigrants Municipality & $\begin{array}{c}0.19 \\
{[0.05]}\end{array}$ & $\begin{array}{c}0.19 \\
{[0.05]}\end{array}$ & $\begin{array}{c}0.19 \\
{[0.05]}\end{array}$ & $\begin{array}{c}0.19 \\
{[0.05]}\end{array}$ & $\begin{array}{c}0.19 \\
{[0.05]}\end{array}$ & $\begin{array}{c}0.19 \\
{[0.05]}\end{array}$ & $\begin{array}{c}0.18 \\
{[0.05]}\end{array}$ & $\begin{array}{c}0.19 \\
{[0.05]}\end{array}$ \\
\hline Public Sector & 0.23 & 0.14 & 0.22 & 0.13 & 0.24 & 0.14 & 0.24 & 0.15 \\
\hline Staffing Company & 0.11 & 0.06 & 0.08 & 0.06 & 0.12 & 0.06 & 0.14 & 0.06 \\
\hline Workplace Location: Stockholm & 0.82 & 0.80 & 0.83 & 0.79 & 0.81 & 0.80 & 0.79 & 0.81 \\
\hline
\end{tabular}

Notes: This table documents the mean characteristics for firms that did invite the applicant, and for those that did not. For continuous variables, standard deviations are reported in parenthesis. Native $\mathbf{S}$ = native with a Swedish sounding name. Native $\mathrm{M}=$ native with a Middle Eastern sounding name.

Table A2 Differences in callback rate and occupational characteristics.

\begin{tabular}{|c|c|c|c|c|c|c|}
\hline \multirow[b]{2}{*}{ Occupation } & \multicolumn{2}{|c|}{ Difference in callback rate } & \multirow[b]{2}{*}{$\begin{array}{c}\text { Share } \\
\text { of } \\
\text { females } \\
(\%)\end{array}$} & \multirow[b]{2}{*}{$\begin{array}{c}\text { Share of } \\
\text { foreign } \\
\text { born } \\
(\%)\end{array}$} & \multirow[b]{2}{*}{$\begin{array}{l}\text { Skill } \\
\text { requirement }\end{array}$} & \multirow[b]{2}{*}{$\begin{array}{l}\text { Proxy for labour } \\
\text { market tightness }\end{array}$} \\
\hline & $\begin{array}{c}\text { Native S } \\
\text { and } \\
\text { native M }\end{array}$ & $\begin{array}{l}\text { Native M } \\
\text { and } \\
\text { immigrant }\end{array}$ & & & & \\
\hline Teachers (math and science) & 0.30 & 0.17 & 76 & 9 & 3 & 0.63 \\
\hline Construction Workers & 0.29 & 0.04 & 1 & 5 & 2 & 0.44 \\
\hline Computer Professionals & 0.23 & 0.14 & 24 & 8 & 3 & 0.63 \\
\hline Motor Vehicle Drivers & 0.23 & -0.03 & 7 & 12 & 2 & 0.42 \\
\hline Nurses & 0.17 & 0.01 & 91 & 10 & 3 & 0.48 \\
\hline Restaurant Workers & 0.17 & 0.04 & 68 & 20 & 1 & 0.28 \\
\hline Accountants & 0.17 & 0.02 & 75 & 7 & 3 & 0.34 \\
\hline Business Sales Assistants & 0.16 & 0.05 & 38 & 6 & 2 & 0.39 \\
\hline Shop Sales Assistants & 0.15 & 0.00 & 76 & 8 & 2 & 0.18 \\
\hline Teachers Secondary School & 0.15 & 0.06 & 53 & 8 & 3 & 0.44 \\
\hline Preschool Teachers & 0.11 & 0.10 & 92 & 7 & 3 & 0.60 \\
\hline
\end{tabular}

Notes: This table reports, for each occupation, the difference in callback rate between the native with a Swedish sounding name (Native S) and the native with a Middle Eastern sounding name (Native M) and between the native $\mathrm{M}$ and the immigrant together with the share of females (taken from Statistics Sweden, 2003), the share of foreign born (taken from Statistics Sweden, 2003), the skill requirement, and a proxy for labour market tightness (the callback rate for the native with a Swedish sounding name). The required skill/level of education in each occupation is defined as $3=$ higher education. $2=$ secondary education and $1=$ primary education. 


\section{Appendix B}

Example application for the immigrant - computer professionals (own translation)

\section{Job Application}

My name is Mohamed Ahmed, I am 29 years old, and I moved to Sweden from Iran 2001. Today I live in Stockholm together with my spouse. After I arrived to Sweden I quickly got a trainee job at IMS Data AB. After about six month, the trainee job became a regular full-time employment.

During the more than four years I spent at IMS AB I have worked in both small and large projects and participated in software development where data processing often have had a central role and therefore I possess MS SQL at a very qualified level. The development environment at the company was .NET and Visual Basic was the programming language most frequently used. Except database programming I also have a lot of experience of development of applications and Web programming. Hence, I master C++, Java/JavaScript as well as HTML and XML. Through projects where I had own responsibility I am used to manage documentation and have customer contact.

When I arrived to Sweden, it was very important for me to learn Swedish as soon as possible. Today I speak, read, and write Swedish unhindered. My education obtained in Teheran has been evaluated by the Swedish National Agency for Higher Education and corresponds to a Master of Science in Engineering with specialisation in information technology.

If I would try to describe myself, I believe I am a positive thinking, patient person who never loses control over a job assignment. My analytical ability have probably been developed during the university studies and the years I have worked as a system developer. In the spare time, I appreciate exercising and spending time with my spouse and my friends.

It would be great if I could have the opportunity to visit for an interview, then I will verify my excellent grades and references as well.

Mohamed Ahmed 
Address: Mohamed Ahmed, Östervägen 44 A, first floor, 16955 Solna;

Email: Mohamed--Ahmed@hotmail.com;

Tel. $08-214608$

\section{CV \\ Mohamed Ahmed}

\section{Education}

Allameh Tabatabai University, Teheran, Iran, 1996 2000

Master of Science in Engineering: The Swedish National Agency for Higher Education has verified that my education corresponds to a Master of Science in Engineering with specialization in Information Technology

Azar och Mofateh secondary school, Teheran, Iran, 1992-1995

Natural Science Line: Three year education at secondary school with specialization in Natural Science

Komvux, Norrköping, 2001

SFI (Swedish language course) C and D: Evening classes for adult immigrants who wish to learn the Swedish language

Work Experience

IMS Data AB, Norrköping, 2002-2006

System developer: System developing, database developing and data processing as well as web oriented programming

Shop, Teheran, Iran, 1995-1997

Shops sales assistant: Part time work during studies

\section{Other Qualifications}

Language

Persian mother tongue, Swedish and English fluent

\section{Computer Skills}

Operating Systems: Very good knowledge in UNIX, Win 95/98/ME/2000/XP.

Programming: Very good knowledge in $\mathrm{VB}, \mathrm{C}++, \mathrm{C}$, J2EE, Applets, JSP, JDBC, XML and HTML

Applications: Very good knowledge in Word, Excel, Microsoft Visual Studio .Net

Databases: Very good knowledge in script language $\mathrm{SQL}$ and in programming interface ODBC.

Driving license

B: passenger car 
Example application for the natives - computer professionals (own translation)

\section{Regarding the advertised job opening}

Hello,

First I would like to introduce myself, my name is Erik Karlsson, I am 28 years old and live in Stockholm.

I have previously worked for a company called EssNet $\mathrm{Ab}$ for about four years. My job tasks there were to design, implement as well as test various financial applications. Most programming was conducted in a Java J2EE environment. However, a lot of development was also performed using $\mathrm{C} / \mathrm{C}++$ and Visual Basic .Net. From time to time, I also participated in projects that were more web oriented and connected to databases. Therefore, I also have experience of ASP, JSP and MS SQL.

As part of my qualifications, I also count my great job satisfaction and that I never leave any task half finished. I have the ability to work independent and take own initiatives. From my previous work place, I am used to co-operate and listen to others opinions in order to obtain the best possible result.

When it comes to education, I am a Master of Science in Engineering with specialization in computer systems and I graded from Uppsala University.

Since I am a very social person, I spend most of my spare time together with my girlfriend, the rest of my family and with my friends. Another great interest of mine is travelling. I look forward to have the opportunity to tell you more about myself and bring my excellent references to a meeting in person.

Best Regards,

Erik

Erik Karlsson

Tallgatan 26 D

17269 Sunbyberg

Tel. 08 - 317004

Email: erik_m_karlsson@yahoo.se 


\section{List of Qualifications}

\section{Education}

Uppsala University

1997-2001

Master of Science in Engineering

with specialisation in computer systems

Secondary School

$1994-1997$

Linnéskolan, Uppsala

Natural Science Line

\section{Employments}

System Developer

2002-2006

EssNet AB,

Postman,

Posten, Uppsala, part time work during studies

\section{Computer Skills}

SQL, ODBC, UNIX, Win 2000, XP, Java, C++, C, Visual Basic, ASP, Microsoft Visual Studio .Net, EViews, and MatLab.

\section{Other Qualifications:}

Driving License B Obtained 1996

Language: Swedish, English 
Table 1. Descriptive results for correspondence testing.

\begin{tabular}{|c|c|c|c|c|c|c|c|}
\hline & \multicolumn{4}{|c|}{ Invited } & \multicolumn{3}{|c|}{ Callback rate } \\
\hline & $\begin{array}{c}\text { None } \\
(1)\end{array}$ & $\begin{array}{l}\text { Both } \\
(2)\end{array}$ & $\begin{array}{c}\text { Only first } \\
\text { (3) }\end{array}$ & $\begin{array}{c}\text { Only second } \\
(4)\end{array}$ & $\begin{array}{l}\text { First } \\
(5)\end{array}$ & $\begin{array}{c}\text { Second } \\
(6)\end{array}$ & $\begin{array}{c}\text { Difference } \\
(5)-(6)\end{array}$ \\
\hline \multicolumn{8}{|c|}{ Teachers (math and science), Jobs $=30$} \\
\hline Native $S$ vs. Native M & 11 & 10 & 9 & 0 & 0.63 & 0.33 & 0.30 \\
\hline Native M vs. Immigrant & 19 & 4 & 6 & 1 & 0.33 & 0.16 & 0.17 \\
\hline \multicolumn{8}{|l|}{ Construction Workers, Jobs=48 } \\
\hline Native S vs. Native M & 26 & 6 & 15 & 1 & 0.44 & 0.15 & 0.29 \\
\hline Native M vs. Immigrant & 38 & 2 & 5 & 3 & 0.15 & 0.11 & 0.04 \\
\hline \multicolumn{8}{|l|}{ Computer Professionals, Jobs $=78$} \\
\hline Native S vs. Native M & 27 & 29 & 20 & 2 & 0.63 & 0.40 & 0.23 \\
\hline Native M vs. Immigrant & 44 & 17 & 14 & 3 & 0.40 & 0.26 & 0.14 \\
\hline \multicolumn{8}{|l|}{ Motor Vehicle Drivers, Jobs $=78$} \\
\hline Native S vs. Native M & 43 & 13 & 20 & 2 & 0.42 & 0.19 & 0.23 \\
\hline Native M vs. Immigrant & 59 & 13 & 2 & 4 & 0.19 & 0.22 & -0.03 \\
\hline \multicolumn{8}{|l|}{ Nurses, Jobs $=150$} \\
\hline Native $S$ vs. Native $M$ & 73 & 43 & 30 & 4 & 0.48 & 0.31 & 0.17 \\
\hline Native M vs. Immigrant & 93 & 35 & 12 & 10 & 0.31 & 0.30 & 0.01 \\
\hline \multicolumn{8}{|l|}{ Restaurant Workers, Jobs $=150$} \\
\hline Native S vs. Native M & 101 & 10 & 32 & 7 & 0.28 & 0.11 & 0.17 \\
\hline Native M vs. Immigrant & 130 & 8 & 9 & 3 & 0.11 & 0.07 & 0.04 \\
\hline \multicolumn{8}{|l|}{ Accountants, Jobs=138 } \\
\hline Native S vs. Native M & 89 & 20 & 26 & 3 & 0.34 & 0.17 & 0.17 \\
\hline Native M vs. Immigrant & 106 & 11 & 12 & 9 & 0.17 & 0.15 & 0.02 \\
\hline \multicolumn{8}{|c|}{ Business Sales Assistants, Jobs $=258$} \\
\hline Native S vs. Native M & 148 & 51 & 50 & 9 & 0.39 & 0.23 & 0.16 \\
\hline Native M vs. Immigrant & 187 & 36 & 24 & 11 & 0.23 & 0.18 & 0.05 \\
\hline \multicolumn{8}{|l|}{ Shop Sales Assistants, Jobs $=150$} \\
\hline Native S vs. Native M & 120 & 3 & 25 & 2 & 0.18 & 0.03 & 0.15 \\
\hline Native M vs. Immigrant & 140 & 0 & 5 & 5 & 0.03 & 0.03 & 0.00 \\
\hline \multicolumn{8}{|c|}{ Teachers Secondary School, Jobs $=48$} \\
\hline Native $S$ vs. Native M & 24 & 11 & 10 & 3 & 0.44 & 0.29 & 0.15 \\
\hline Native M vs. Immigrant & 30 & 7 & 7 & 4 & 0.29 & 0.23 & 0.06 \\
\hline \multicolumn{8}{|l|}{ Preschool Teachers, Jobs $=186$} \\
\hline Native $S$ vs. Native $M$ & 66 & 84 & 28 & 8 & 0.60 & 0.49 & 0.11 \\
\hline Native M vs. Immigrant & 81 & 60 & 32 & 13 & 0.49 & 0.39 & 0.10 \\
\hline \multicolumn{8}{|l|}{ Total, Jobs=1314 } \\
\hline Native $S$ vs. Native $M$ & 728 & 280 & 265 & 41 & 0.41 & 0.24 & 0.17 \\
\hline Native M vs. Immigrant & 927 & 193 & 128 & 66 & 0.24 & 0.20 & 0.04 \\
\hline
\end{tabular}

Notes: This table reports, for each occupation and in total, in how many cases none of the applicants, both applicants, only the first or only the second applicant was invited to interview as well as the callback rates for the applicants and the difference in callback rate. Native $\mathrm{S}=$ Native with a Swedish sounding name. Native $\mathrm{M}=$ Native with a Middle Eastern sounding name 
Table 2 . The probability of a callback to an interview.

\begin{tabular}{|c|c|c|c|}
\hline Occupation & $\begin{array}{c}\text { Constant } \\
\text { (Probability of a callback } \\
\text { for the native with a } \\
\text { Middle Eastern sounding name) }\end{array}$ & $\begin{array}{c}\text { Difference } \\
\text { Native with a } \\
\text { Swedish sounding name }\end{array}$ & $\begin{array}{l}\text { Difference } \\
\text { Immigrant }\end{array}$ \\
\hline Teachers (math and science) & $0,33^{* * *}$ & $0,30^{* * *}$ & $-0,17^{*}$ \\
\hline Applications $=90$ & {$[0,09]$} & {$[0,09]$} & {$[0,09]$} \\
\hline Construction Workers & $0,15^{\star * *}$ & $0,29^{\star * *}$ & $-0,04$ \\
\hline Applications $=144$ & {$[0,05]$} & {$[0,07]$} & {$[0,06]$} \\
\hline Computer Professionals & $0,40^{* * *}$ & $0,23^{* * *}$ & $-0,14^{* * *}$ \\
\hline Applications $=234$ & {$[0,06]$} & {$[0,05]$} & {$[0,05]$} \\
\hline Motor Vehicle Drivers & $0,19^{* * *}$ & $0,23^{* * *}$ & 0,03 \\
\hline Applications=234 & {$[0,05]$} & {$[0,05]$} & {$[0,03]$} \\
\hline Nurses & $0,31^{* * *}$ & $0,17^{* * *}$ & $-0,01$ \\
\hline Applications $=450$ & {$[0,04]$} & {$[0,04]$} & {$[0,03]$} \\
\hline Restaurant Workers & $0,11^{* * *}$ & $0,17^{* * *}$ & $-0,04^{*}$ \\
\hline Applications $=450$ & {$[0,03]$} & {$[0,04]$} & {$[0,02]$} \\
\hline Accountants & $0,17^{\star * *}$ & $0,17^{\star \star *}$ & $-0,02$ \\
\hline Applications $=414$ & {$[0,03]$} & {$[0,04]$} & {$[0,03]$} \\
\hline Business Sales Assistants & $0,23^{* * *}$ & $0,16^{* * *}$ & $-0,05^{\star *}$ \\
\hline Applications=774 & {$[0,03]$} & {$[0,03]$} & {$[0,02]$} \\
\hline Shop Sales Assistants & $0,03^{* *}$ & $0,15^{* * *}$ & 0,00 \\
\hline Applications $=450$ & {$[0,01]$} & {$[0,03]$} & {$[0,02]$} \\
\hline Teachers Secondary School & $0,29^{* * *}$ & $0,15^{*}$ & $-0,06$ \\
\hline Applications $=144$ & {$[0,07]$} & {$[0,07]$} & {$[0,07]$} \\
\hline Preschool Teachers & $0,49^{* * *}$ & $0,11^{* * *}$ & $-0,10^{* * *}$ \\
\hline Applications $=558$ & {$[0,04]$} & {$[0,03]$} & {$[0,04]$} \\
\hline Total & $0,24^{* * *}$ & $0,17^{* \star *}$ & $-0,05^{\star \star *}$ \\
\hline Applications $=3942$ & {$[0,01]$} & {$[0,01]$} & {$[0,01]$} \\
\hline \multicolumn{4}{|c|}{ 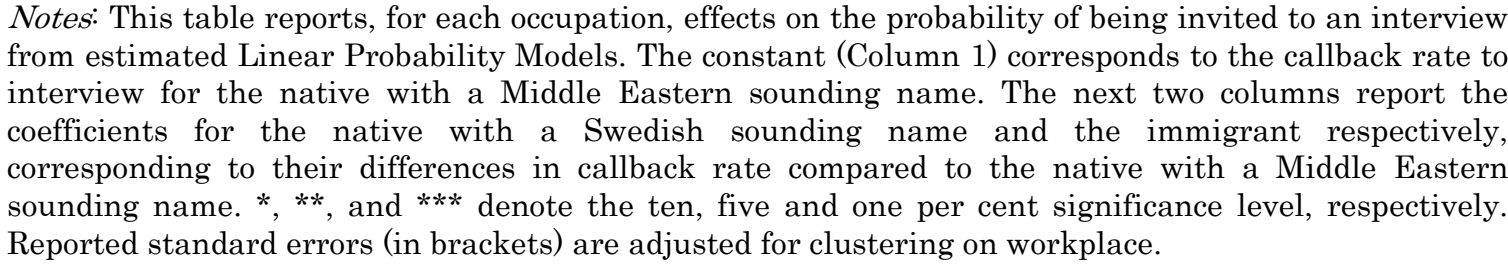 } \\
\hline
\end{tabular}


Table 3. Factors influencing differences in callbacks. Marginal effects

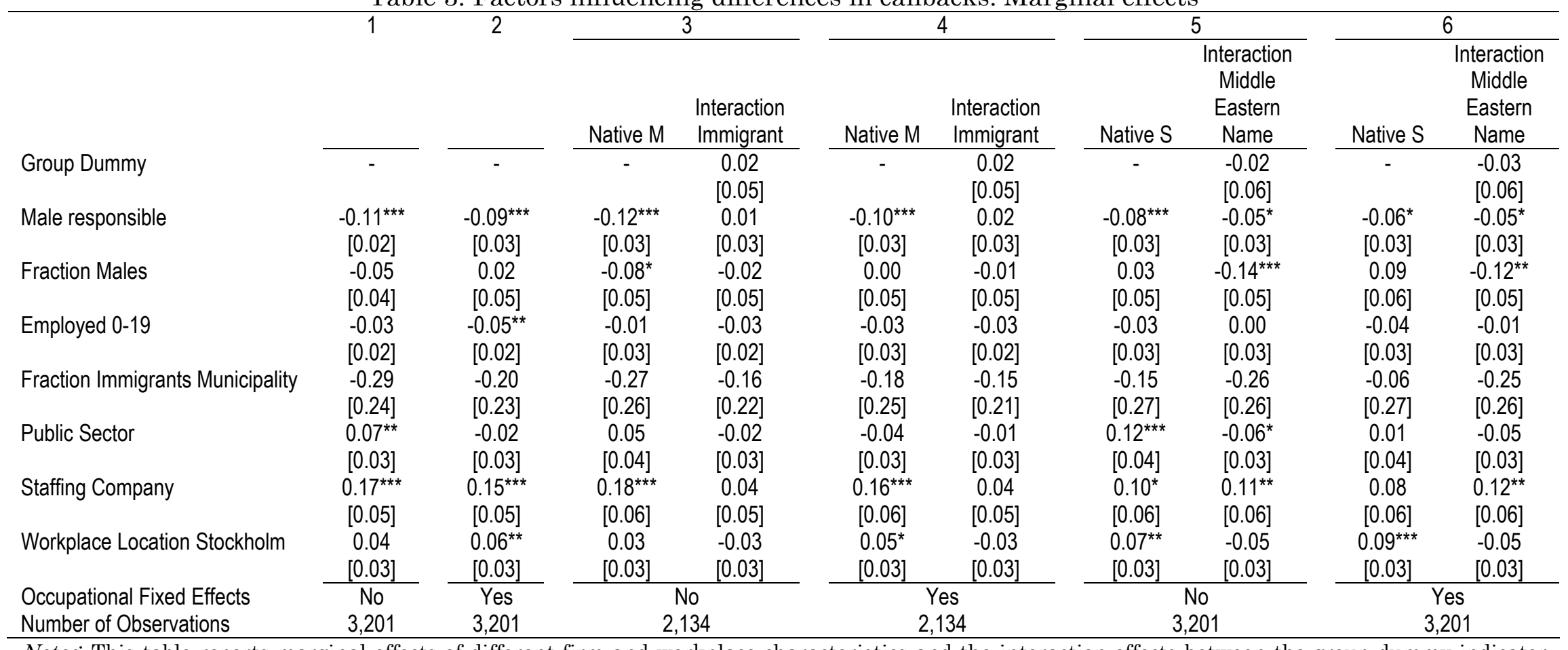

Notes: This table reports marginal effects of different firm and workplace characteristics and the interaction effects between the group dummy indicator and different firm and workplace characteristics on the probability of being invited to interview (from estimated probit models). Native $\mathrm{S}=\mathrm{Native}$ with a Swedish sounding name. Native $\mathrm{M}=$ Native with a Middle Eastern sounding name. In Model 5 and 6 , the observations of the native with a Middle Eastern sounding name and the immigrants are merged to form the new group of individuals with Middle Eastern sounding names. ***, and *** denote the ten, five and one per cent significance level respectively. Reported standard errors (in brackets) are adjusted for clustering on workplace. 